\title{
sciendo
}

\section{A BLEND OF HERBAL ESSENTIAL OILS ENHANCED THE GROWTH PERFORMANCE, BLOOD BIO-IMMUNOLOGY TRAITS, AND INTESTINAL HEALTH OF NILE TILAPIA (OREOCHROMIS NILOTICUS)}

Fawzy I. Magouz ${ }^{1}$, Mohammed T. Shehab El-Din², Asem A. Amer ${ }^{3}$, Mahmoud S. Gewaily ${ }^{4}$ Wafaa A. El-Dahdoh ${ }^{1}$, Mahmoud A.O. Dawood ${ }^{1,5}$

\author{
${ }^{1}$ Department of Animal Production, Faculty of Agriculture, Kafrelsheikh University, 33516, Kafrelsheikh, Egypt \\ ${ }^{2}$ Department of Fish Health, Sakha Aquaculture Research Unit, Central Laboratory for Aquaculture Research, Abbassa, \\ Agriculture Research Center, Egypt \\ ${ }^{3}$ Sakha Aquaculture Research Unit, Central Laboratory for Aquaculture Research, Abbassa, Sharkia, Sakha Aquaculture Research Unit, \\ Kafrelsheikh, Egypt \\ ${ }^{4}$ Department of Anatomy and Embryology, Faculty of Veterinary Medicine, Kafrelsheikh University \\ ${ }^{5}$ The Center for Applied Research on the Environment and Sustainability, The American University in Cairo, 11835, Cairo, Egypt \\ •Corresponding author: Mahmoud.dawood@agr.kfs.edu.eg
}

\begin{abstract}
Nile tilapia were fed four levels $(0,0.25,0.5$, and $1 \mathrm{ml} / \mathrm{kg})$ of a liquid blend of herbal essential oils (EOs) containing carvacrol, oregano, 1,8 cineol, thymol, pinene, pinene $\beta$, limonene, and propylene glycol for 60 days. The results showed higher final weight, weight gain, and specific growth rate $(\mathrm{P}<\mathbf{0 . 0 5})$ in fish delivered 0.25 and $0.5 \mathrm{ml} \mathrm{EOs} / \mathrm{kg}$ than the control. However, the feed conversion ratio was markedly reduced in fish fed 0.5 and $1 \mathrm{ml} \mathrm{EOs/kg}(\mathrm{P}<0.05)$. Lipase showed enhanced activity in fish subjected to a blend of EOs, while fish fed $0.5 \mathrm{ml} / \mathrm{kg}$ of EOs blend had higher amylase activity $(\mathrm{P}<0.05)$ than the other levels. Lysozyme activity and superoxide dismutase showed a higher value in fish that received $0.5 \mathrm{ml} \mathrm{EOs} / \mathrm{kg}$. Additionally, phagocytic and catalase activities were enhanced in fish that received 0.5 and $1 \mathrm{ml} / \mathrm{kg}$ while phagocytic index was enhanced in fish fed $1 \mathrm{ml} / \mathrm{kg}(\mathrm{P}<0.05)$. Interestingly, the total immunoglobulin level was markedly higher, while malondialdehyde was lower in EOs-subjected fish $(\mathrm{P}<\mathbf{0 . 0 5})$ than in control. The histomorphology appearance of the intestine, liver, and spleen was enriched in EOs-treated fish compared to the control fish. In conclusion, the growth performance, feed efficiency, and blood bio-immunological indices were best in fish fed 0.5-1 ml of EOs blend per kg.
\end{abstract}

Key words: phytogenics, blue aquaculture, tilapia, health condition, production

The current aquaculture practices focus on the suitability of farming conditions to maintain the optimum conditions for finfish growth (Metian et al., 2020). This includes the necessity of producing nutritional feed which contains essential nutrients and functional additives (Ahmadifar et al., 2021; Dawood et al., 2018). The inclusion of healthy substances in aquafeed is suggested as a safe alternative to antibiotics that are massively applied to combat pathogen invaders (Erkinharju et al., 2021; Lulijwa et al., 2020). Indeed, feed additives as natural growth and immunomodulatory agents are necessary for aquaculture to produce safe and organic seafood for humanity (Elumalai et al., 2020). A wide range of additives was used in aquaculture, such as probiotics, prebiotics, and immunostimulants (Dawood, 2021; Habiba et al., 2021). Besides, medicinal herbs and their extracts called "phylogenetics" are recommended due to sedative, growthpromoting, immunostimulant, antioxidative, and antidiseases effects (Aydın and Barbas, 2020; Zhu, 2020).

Herbal essential oils (EOs) are the pure extract of medicinal plants with rich fragrances, flavors, polyphenols, antibacterial and antiparasitic effects (Dawood et al., 2021). Many studies tackled the influences of EOs on the growth, immune, and antioxidant responses of finfish species (Brandão et al., 2021). Markedly, the results displayed positive effects of using EOs on the general health status and well-being involved in raising the resistance of aquatic species against infectious diseases (Alagawany et al., 2020; Dinardo et al., 2020). Carvacrol, oregano, 1,8 cineol, thymol, pinene, pinene $\beta$, limonene, propylene glycol, menthol, curcumin EOs are commonly used in aquaculture and are known for their beneficial influences on finfish performances (Aydin and Barbas, 2020; Hernández-Contreras and Hernández, 2020). In most cases, these EOs were added to aquafeed individually (Sönmez et al., 2015), but using combined mixtures of EOs is scarcely investigated. The application of combined mixtures of EOs is supposed to be more efficient than individual forms associated with the complementary derivatives that can synergistically affect the well-being of finfish (Costa et al., 2020; Ning et al., 2021).

Nile tilapia (Oreochromis niloticus) becomes the main commercial finfish species in the whole world because of its delicious taste, profitable value, and resistance to unstable farming conditions (Mengistu et al., 2020). The inclusion of EOs in tilapia diets was previously applied, 
such as oregano (Mabrok and Wahdan, 2018), thymol (Valladão et al., 2019), orange peel (Acar et al., 2015), menthol (Magouz et al., 2021), fennel (Abdel Rahman et al., 2017), Aloysia triphylla (de Souza et al., 2020), and ginger (Brum et al., 2017). The results concluded positive effects of incorporating EOs in tilapia diets on feed utilization, digestion capacity, the abundance of beneficial microorganisms in the intestine, metabolic functions, immune response, antioxidative status, and resistance against infection. Further, EOs increased the resistance of tilapia against unstable farming conditions and exposure to toxins and xenobiotics (Magouz et al., 2021; Postay et al., 2021). Accordingly, this study was carried out to test the possible effects of using a mixture of EOs on the growth, blood health, antioxidative and immune responses of Nile tilapia.

\section{Material and methods}

\section{Ethical approval}

The experiments of the current study were approved by the Faculty of Agriculture, Kafrelsheikh University, Egypt.

\section{Trial conditions}

A stock of Nile tilapia juveniles was obtained from a private farm in Kafrelsheikh and kept in the Sakha Aquaculture Research Unit, Kafrelsheikh. Fish were adapted to the lab conditions in a $1000 \mathrm{~L}$ fiberglass tank and fed a $300 \mathrm{~g} / \mathrm{kg}$ crude protein diet for ten days. Afterward, fish with similar sizes of $19.6 \pm 0.51 \mathrm{~g} /$ fish were stocked in twelve glass aquaria $(60 \mathrm{~L})$ at the rate of 20 fish/aquarium. Triple aquaria were considered representative for one group, and each one was supported by continuous aeration sourced from electric aerators. The aquaria were provided with chlorine-free water, where half of the water was replaced daily. Fish were fed the test diets for 60 days twice a day (08:00 and 15:00) at 3\% of the body weight gain. The weight gain was checked biweekly, and the level of feeding was recalculated accordingly. The water quality was checked regularly and recorded: temperature $\left(25.12 \pm 1.1^{\circ} \mathrm{C}\right)$, dissolved oxygen $(6.22 \pm$ $0.31 \mathrm{mg} / \mathrm{L}), \mathrm{pH}(7.6 \pm 0.2)$, and total-ammonia nitrogen $(0.003 \pm 0.001 \mathrm{~g} / \mathrm{L})$.

\section{Test diets}

Four isonitrogenous and isocaloric diets were prepared to satisfy the nutritional requirements of Nile tilapia juveniles (Table 1) (NRC, 2011). The basal diet was formulated with fish meal, soybean meal, yellow corn, wheat bran, rice bran, and mineral-vitamin premixes (Table 1). The ingredients were well mixed and divided for four sets of diets where each one was supplemented with a blend of liquid essential oils (EOs) containing carvacrol (45 g/L), oregano (45 g/L), 1,8 cineol (16 g/L), thymol (39.2 g/L), pinene $(4.6 \mathrm{~g} / \mathrm{L})$, pinene $\beta(2.6 \mathrm{~g} / \mathrm{L})$, limonene (3 g/L), and propylene glycol (150 g/L) (TRI VIR, Tri-
Pharma Company, Egypt) at 0, 0.25, 0.5, and $1 \mathrm{ml} / \mathrm{kg}$. Fish oil was further mixed with all ingredients in the presence of water then the whole mixture was pelleted in the lab pelleting machine to produce a dough $(2-3 \mathrm{~mm})$. The prepared pellets were spread and kept at room temperature until fully dry, then stored in plastic bags and left at $4^{\circ} \mathrm{C}$ throughout the trial. The chemical composition of the diets was checked by following the standard methods (AOAC, 2012).

Table 1. Chemical composition and calculated analysis of the basal experimental diet

\begin{tabular}{lrlr}
\hline \multicolumn{1}{c|}{ Ingredients $(\mathrm{g} / \mathrm{kg})$} & \multicolumn{2}{c}{$\begin{array}{c}\text { Chemical composition } \\
(\mathrm{g} / \mathrm{kg})\end{array}$} \\
\hline $\begin{array}{l}\text { Fish meal } \\
(62 \% \text { crude protein) }\end{array}$ & 100 & Crude protein & 303.2 \\
Soybean meal & & & 57.4 \\
$(45 \%$ crude protein $)$ & 450 & Crude lipids & 35.5 \\
Yellow corn & 120 & Ash & 51.2 \\
Wheat bran & 120 & Fibers & 18.9 \\
Rice bran & 120 & Gross energy $(\mathrm{MJ} / \mathrm{kg})^{2}$ & \\
Fish oil & 50 & & \\
Vitamin and mineral mix ${ }^{1}$ & 20 & \\
Dicalcium phosphate & 10 & \\
Vitamin C & 10 & \\
Total & 1000 & \\
\hline
\end{tabular}

${ }^{1}$ Vitamin and mineral mixture detailed by Dawood et al. (2020).

${ }^{2}$ Gross energy was calculated based on protein, lipid, and carbohydrate values as $23.6,39.5$, and $17.2 \mathrm{KJ} / \mathrm{g}$, respectively.

\section{Final sampling}

At the end of the trial, fish were deprived of feed for 24 hours to accurately detect the final weight (FBW), length, and number. The weight gain (WG), specific growth rate (SGR), and feed conversion ratio (FCR) were calculated using the following equations:

$$
\begin{gathered}
W G=100 \times(F B W-\text { initial weight }(I B W, g)) / I B W(g) \\
S G R(\text { percent/day })=100 \times(\ln F B W(g)-\ln I B W(g)) / \\
\text { days } \\
F C R=\text { feed intake }(g) / W G(g) \\
\text { Survival }(\%)=100 \times \text { final fish number/initial fish } \\
\text { number } \\
\text { Condition factor }(C F, \%)=\text { fish weight }(g) /(\text { fish length, } \\
\mathrm{cm})^{3} \times 100
\end{gathered}
$$

Three fish from each aquarium were collected, anesthetized (100 mg/L tricaine methanesulfonate), and bled from the caudal vein by 2.5 syringes for blood collection. Half of the blood was released in heparinized tubes for hematological analysis, while the remaining blood was kept in non-heparinized tubes for serum collection. Blood was kept for 3 hours to clot, centrifuged (3000 $\mathrm{rpm} / 15 \mathrm{~min}$ at $4^{\circ} \mathrm{C}$ ) to separate the serum. The liver and viscera were collected and weighed to calculate the hepatosomatic (HSI) and viscera somatic (VSI) indices. The collected serum was kept at $-20^{\circ} \mathrm{C}$ for further analysis. Besides, three fish per replicate were dissected to col- 
lect the intestines, spleens, and livers for the histological study.

$$
\begin{gathered}
\text { HSI }(\%)=\text { liver weight }(g) / \text { fish weight }(g) \times 100 ; \text { VSI }(\%) \\
=\text { viscera weight }(g) / \text { fish weight }(g) \times 100
\end{gathered}
$$

\section{Experimental analysis}

White blood cell (WBC) and red blood cell (RBC) counts, and hemoglobin concentration $(\mathrm{Hb})$ were done following standard procedure (Houston, 1990). Differential WBC and RBC counts were conducted on Giemsastained blood smears. Packed cell volume (PCV, \%) was determined by the microhematocrit method.

Serum total proteins and albumins were determined according to Doumas et al. (1981) and Doumas and Biggs (1972), while globulins content was calculated mathematically. Blood lipase activity, amylase activity, aspartate aminotransferase (AST), alanine aminotransferase (ALT), immunoglobulin M (IgM), total cholesterol, creatinine, urea, uric acid, and triglycerides were detected by RA-50 chemistry analyzer (Bayer) using readymade chemicals (kits) supplied by Spinreact Co. Spain, following the manufacturer's instructions.

Analysis of serum lysozyme activity was performed using turbidimetric assay, according to Ellis et al. (1990), based on the lysis of Gram-positive bacterium Micrococcus lysodeikticus (Sigma, USA). Leukocyte phagocytic function was analyzed by following Cai et al. (2004). The number of leukocytes engulfed bacteria was counted as percentages with the total number of leukocytes in the smear from the phagocytosis assay. The phagocytic activity and phagocytic index were determined as described by Kawahara et al. (1991).

Superoxide dismutase, catalase, and malondialdehyde levels in serum were measured using diagnostic reagent kits following the manufacturer's (Cusabio Biotech Co., Ltd.; China) instructions.

\section{Histomorphology}

The histological examination was adopted according to Gewaily and Abumandour (2020). The dissected intestine, spleen, and liver samples were cut into pieces of approximately $0.5 \mathrm{~cm}^{3}$ and fixed in neutral buffered formaldehyde $10 \%$ solution for $24 \mathrm{~h}$. The samples were then dehydrated in ascending grades of alcohol, cleared with xylene, and embedded in paraffin wax. Then five $\mu \mathrm{m}$ thick sections were cut using Leica rotatory microtome (RM 20352035; Leica Microsystems, Wetzlar, Germany) and stained with hematoxylin and eosin. Finally, the tissue sections were examined using a BX50/BXFLA microscope (Olympus, Tokyo, Japan).

\section{Statistical analysis}

Shapiro-Wilk and Levene tests confirmed normal distribution and homogeneity of variance. The obtained data were subjected to one-way ANOVA. Differences between means were tested at $\mathrm{P}<0.05$ level using the Duncan test as a post-doc test. All the statistical analyses were done via SPSS version 22 (SPSS Inc., IL, USA).

\section{Results}

\section{Growth and somatic indices}

The growth performance of Nile tilapia displayed higher FBW, WG, and SGR $(\mathrm{P}<0.05)$ in fish delivered 0.25 and $0.5 \mathrm{ml} \mathrm{EOs} / \mathrm{kg}$ than the control (Table 2). The feed amount showed higher consumption in fish fed 0.25 and $0.5 \mathrm{ml} \mathrm{EOs} / \mathrm{kg}(\mathrm{P}<0.05)$ than those fed 0 and $1 \mathrm{ml} / \mathrm{kg}$ diet (Table 2). However, the FCR was markedly reduced in fish fed 0.5 and $1 \mathrm{ml} \mathrm{EOs} / \mathrm{kg}(\mathrm{P}<0.05)$ than the control without differences with those fed $0.25 \mathrm{ml} / \mathrm{kg}$ (Table 2). No marked alterations $(\mathrm{P}>0.05)$ were observed in the survival rate, and somatic indices (CF, HSI, and VSI) of Nile tilapia fed varying levels of the blend of EOs (Table 2).

Table 2. Effect of herbal EOs blend $(\mathrm{ml} / \mathrm{kg})$ on the growth performance of Nile tilapia

\begin{tabular}{l|c|c|c|c}
\hline \multicolumn{1}{c|}{ Item } & 0 & 0.25 & 0.5 & P-value \\
\hline IBW (g) & $19.88 \pm 0.02$ & $19.90 \pm 0.00$ & $19.83 \pm 0.02$ & $19.85 \pm 0.03$ \\
FBW (g) & $36.67 \pm 1.40 \mathrm{a}$ & $40.98 \pm 0.37 \mathrm{~b}$ & $41.73 \pm 1.04 \mathrm{~b}$ & $39.06 \pm 0.54 \mathrm{ab}$ \\
WG (\%) & $84.39 \pm 6.91 \mathrm{a}$ & $105.95 \pm 1.87 \mathrm{~b}$ & $110.38 \pm 5.09 \mathrm{~b}$ & $96.76 \pm 2.54 \mathrm{ab}$ \\
SGR (\%/day) & $1.02 \pm 0.06 \mathrm{a}$ & $1.20 \pm 0.02 \mathrm{~b}$ & $1.24 \pm 0.04 \mathrm{~b}$ & $1.13 \pm 0.02 \mathrm{ab}$ \\
FI (g/fish/60 days) & $23.42 \pm 1.21 \mathrm{a}$ & $29.00 \pm 0.71 \mathrm{~b}$ & $26.66 \pm 1.28 \mathrm{~b}$ & $24.80 \pm 1.06 \mathrm{a}$ \\
FCR & $1.41 \pm 0.07 \mathrm{~b}$ & $1.38 \pm 0.03 \mathrm{ab}$ & $1.22 \pm 0.03 \mathrm{a}$ & 0.023 \\
Survival (\%) & $93.33 \pm 28.48$ & $100 \pm 0$ & $1.29 \pm 0.02 \mathrm{a}$ \\
CF (\%) & $2.37 \pm 0.27$ & $2.00 \pm 0.03$ & $2.36 \pm 0.52$ & 0.016 \\
HSI (\%) & $1.79 \pm 0.20$ & $2.19 \pm 0.50$ & $2.52 \pm 0.74$ & 0.043 \\
VSI (\%) & $1.74 \pm 0.87$ & $2.82 \pm 0.42$ & $3.21 \pm 0.29$ & 0.121 \\
\hline
\end{tabular}

Means \pm S.E. in the same row with different letters differ significantly $(\mathrm{P}<0.05)$. IBW: initial body weight, FBW: final body weight, WG: weight gain, SGR: specific growth rate, FI: feed intake, FCR: feed conversion ratio, CF: condition factor, HSI: hepatosomatic index, VSI: viscera somatic index. 


\section{Activities of digestive enzymes}

Lipase showed enhanced activity in fish fed a blend of EOs in a dose-dependent manner comparing to the control $(\mathrm{P}<0.05)$ (Table 3$)$. The highest lipase activity was in fish fed 0.5 and $1 \mathrm{ml} \mathrm{EOs} / \mathrm{kg}$. Additionally, fish fed $0.5 \mathrm{ml} / \mathrm{kg}$ of EOs blend had higher amylase activity $(\mathrm{P}<0.05)$ than the other levels (Table 3$)$.

\section{Hemato-biochemical indices}

The hematic test results showed higher $\mathrm{Hb}, \mathrm{PCV}, \mathrm{RBCs}$, and WBCs $(\mathrm{P}<0.05)$ in Nile tilapia that received a blend of EOs at the levels of $0.25,0.5$, and $1 \mathrm{ml} / \mathrm{kg}$ compared to the control (Table 4). However, no marked effects of using EOs blend on the blood biochemical traits of Nile tilapia were observed in the present study $(\mathrm{P}>0.05)$ (Table 5).

Table 3. Effect of herbal EOs blend $(\mathrm{ml} / \mathrm{kg})$ on digestive enzyme activity of Nile tilapia

\begin{tabular}{l|c|c|c|c}
\hline Item & 0 & 0.25 & 0.5 & P-value \\
\hline Lipase activity (unit/ml) & $76.53 \pm 2.05 \mathrm{a}$ & $83.90 \pm 3.78 \mathrm{~b}$ & $96.27 \pm 1.55 \mathrm{c}$ & $93.75 \pm 1.87 \mathrm{c}$ \\
Amylase activity (unit/ml) & $94.86 \pm 0.73 \mathrm{a}$ & $96.96 \pm 1.13 \mathrm{a}$ & $107.24 \pm 2.94 \mathrm{~b}$ & $98.99 \pm 0.68 \mathrm{a}$ \\
\hline
\end{tabular}

Means \pm S.E. in the same row with different letters differ significantly $(\mathrm{P}<0.05)$.

Table 4. Effect of herbal EOs blend $(\mathrm{ml} / \mathrm{kg})$ on the hematological traits of Nile tilapia

\begin{tabular}{|c|c|c|c|c|c|}
\hline Item & 0 & 0.25 & 0.5 & 1 & P-value \\
\hline $\mathrm{Hb}(\mathrm{g} / 100 \mathrm{ml})$ & $6.97 \pm 0.29 \mathrm{a}$ & $7.75 \pm 0.16 \mathrm{~b}$ & $8.24 \pm 0.10 \mathrm{~b}$ & $8.41 \pm 0.02 \mathrm{~b}$ & 0.025 \\
\hline $\operatorname{RBCs}\left(10 / \mathrm{mm}^{3}\right)$ & $2.27 \pm 0.08 \mathrm{a}$ & $2.54 \pm 0.06 \mathrm{~b}$ & $2.71 \pm 0.02 \mathrm{~b}$ & $2.74 \pm 0.02 \mathrm{~b}$ & 0.002 \\
\hline $\operatorname{PCV}(\%)$ & $22.33 \pm 0.88 \mathrm{a}$ & $25.00 \pm 0.58 \mathrm{~b}$ & $26.33 \pm 0.33 \mathrm{~b}$ & $26.67 \pm 0.33 \mathrm{~b}$ & 0.036 \\
\hline $\operatorname{MCV}\left(\mu \mathrm{m}^{3} /\right.$ cell $)$ & $98.22 \pm 0.91$ & $98.30 \pm 0.33$ & $97.16 \pm 0.55$ & $97.21 \pm 0.88$ & 0.056 \\
\hline $\mathrm{MCH}$ (pg/cell) & $30.63 \pm 0.19$ & $30.49 \pm 0.24$ & $30.39 \pm 0.33$ & $30.67 \pm 0.20$ & 0.211 \\
\hline $\mathrm{MCHC}(\%)$ & $31.19 \pm 0.33$ & $31.02 \pm 0.32$ & $31.28 \pm 0.32$ & $31.56 \pm 0.36$ & 0.361 \\
\hline WBCs $\left(10 / \mathrm{mm}^{6}\right)$ & $7.31 \pm 0.18 \mathrm{a}$ & $7.91 \pm 0.09 \mathrm{~b}$ & $8.49 \pm 0.27 \mathrm{~b}$ & $10.06 \pm 0.12 \mathrm{~b}$ & 0.001 \\
\hline Heterophils (\%) & $15.00 \pm 1.53$ & $11.33 \pm 0.88$ & $10.67 \pm 0.67$ & $10.00 \pm 0.58$ & 0.621 \\
\hline Lymphocytes (\%) & $76.33 \pm 1.86$ & $79.67 \pm 0.88$ & $80.67 \pm 0.88$ & $81.67 \pm 0.33$ & 0.329 \\
\hline Monocytes (\%) & $6.67 \pm 0.33$ & $7.67 \pm 0.33$ & $7.67 \pm 0.67$ & $7.67 \pm 0.33$ & 0.062 \\
\hline Eosinophils (\%) & $1.00 \pm 0.58$ & $1.00 \pm 0.00$ & $0.67 \pm 0.33$ & $0.33 \pm 0.33$ & 0.104 \\
\hline Basophil (\%) & $1.00 \pm 0.00$ & $0.33 \pm 0.33$ & $0.33 \pm 0.33$ & $0.33 \pm 0.33$ & 0.072 \\
\hline
\end{tabular}

Means \pm S.E. in the same row with different letters differ significantly $(\mathrm{P}<0.05)$. Hb: hemoglobin; RBCs: red blood cells; PCV: packed cell volume; MCV: mean corpuscular volume; $\mathrm{MCH}$ : mean corpuscular hemoglobin; MCHC: mean corpuscular hemoglobin concentration, WBCs: white blood cells.

Table 5. Effect of herbal EOs blend $(\mathrm{ml} / \mathrm{kg})$ on blood biochemical traits of Nile tilapia

\begin{tabular}{|c|c|c|c|c|c|}
\hline Item & 0 & 0.25 & 0.5 & 1 & P-value \\
\hline Glucose (mg/dl) & $9.44 \pm 0.14$ & $9.89 \pm 0.07$ & $10.24 \pm 0.09$ & $9.96 \pm 0.06$ & 0.511 \\
\hline $\operatorname{ALT}(\mathrm{U} / \mathrm{I})$ & $26.55 \pm 0.56$ & $26.32 \pm 0.60$ & $24.13 \pm 1.53$ & $26.66 \pm 1.80$ & 0.203 \\
\hline $\operatorname{AST}(\mathrm{U} / \mathrm{I})$ & $40.33 \pm 0.35$ & $39.40 \pm 0.71$ & $39.61 \pm 0.33$ & $39.25 \pm 0.66$ & 0.059 \\
\hline Total protein $(\mathrm{g} / \mathrm{dl})$ & $2.46 \pm 0.03$ & $2.65 \pm 0.03$ & $2.76 \pm 0.04$ & $2.71 \pm 0.01$ & 0.102 \\
\hline Albumin (g/dl) & $1.30 \pm 0.01$ & $1.35 \pm 0.03$ & $1.41 \pm 0.02$ & $1.37 \pm 0.02$ & 0.062 \\
\hline Globulin (g/dl) & $1.16 \pm 0.03$ & $1.30 \pm 0.04$ & $1.35 \pm 0.04$ & $1.33 \pm 0.02$ & 0.305 \\
\hline Creatinine $(\mathrm{mg} / \mathrm{dl})$ & $0.38 \pm 0.02$ & $0.30 \pm 0.01$ & $0.33 \pm 0.02$ & $0.30 \pm 0.02$ & 0.071 \\
\hline Uric acid (mg/dl) & $0.83 \pm 0.01$ & $0.81 \pm 0.02$ & $0.75 \pm 0.03$ & $0.81 \pm 0.01$ & 0.613 \\
\hline Urea (mg/dl) & $2.28 \pm 0.08$ & $2.29 \pm 0.18$ & $1.86 \pm 0.07$ & $1.97 \pm 0.10$ & 0.501 \\
\hline T-CHO (mg/dl) & $79.11 \pm 0.83$ & $81.94 \pm 0.76$ & $87.99 \pm 1.92$ & $83.61 \pm 1.84$ & 0.081 \\
\hline TG (mg/dl) & $80.82 \pm 0.82$ & $92.95 \pm 1.90$ & $96.19 \pm 3.12$ & $88.19 \pm 1.00$ & 0.064 \\
\hline
\end{tabular}

ALT: alanine aminotransferase, AST: aspartate aminotransferase, T-CHO: total cholesterol, TG: triglycerides. 


\section{Immune and antioxidative responses}

Lysozyme activity showed a higher value in fish that received $0.5 \mathrm{ml} \mathrm{EOs} / \mathrm{kg}(\mathrm{P}<0.05)$ than those that received 0 or $0.25 \mathrm{ml} / \mathrm{kg}$ without significant alterations with $1 \mathrm{ml} / \mathrm{kg}$ (Figure $1 \mathrm{~A}$ ). Additionally, phagocytic activity was enhanced in fish that received 0.5 and $1 \mathrm{ml} / \mathrm{kg}$ while phagocytic index was enhanced in fish fed $1 \mathrm{ml} / \mathrm{kg}$ $(\mathrm{P}<0.05)$ compared to the control (Figure $1 \mathrm{~B}$ and $1 \mathrm{C}$ ). Interestingly, the level of immunoglobulin was markedly higher in EOs-subjected fish at varying levels $(\mathrm{P}<0.05)$ than in control (Figure 1 D).

Superoxide dismutase was enhanced in fish that received $0.5 \mathrm{ml} / \mathrm{kg}$ while catalase was enhanced in fish fed 0.5 and $1 \mathrm{ml} / \mathrm{kg}(\mathrm{P}<0.05)$ compared to the control (Figure $2 \mathrm{~A}$ and $2 \mathrm{~B}$ ). However, malondialdehyde level was meaningfully $(\mathrm{P}<0.05)$ reduced in EOs-subjected fish at varying levels, with the lowest levels being in fish delivered 0.5 and $1 \mathrm{ml} / \mathrm{kg}$ (Figure $2 \mathrm{C}$ ).

\section{Histomorphology}

The histological examination of the intestine in all groups showed normal structure forming of intestinal villi projecting from the intestinal wall. The villi project from the intestinal mucosa and are formed by enterocytes with goblet cells. The lamina propria, tunica muscularis, and serosa of the intestinal wall were intact. The appearance of intestinal villi was enriched in EOs-treated fish via branching and increased length in addition to the lymphoepithelium (Figure $3 \mathrm{~B}-\mathrm{D}$ ).

The hepatopancreas had a normal construction in all fish groups (Figure 4 A-D). The polyhedral hepatocytes were arranged in cords with blood sinusoids. The pancreatic acini were found related with the hepatic part and formed of pancreatic cells and afferent blood vessels. The spongy appearance of the liver in the control fish was improved in the EOs-treated groups, particularly at the low and medium doses $(0.25$ and $0.5 \mathrm{ml} / \mathrm{kg}$ ) (Figure $4 \mathrm{~B}-\mathrm{C}$ ) due to glycogen restoration.

The spleen of the control fish (Figure 5 A) showed normal appearance of red and white pulps. The EOssubjected fish (B, C, and D respectively) displayed increased melanomacrophages and lymphocytic infiltration with the increased dose of EOs mixture (Figure 5 B-D).
(A)

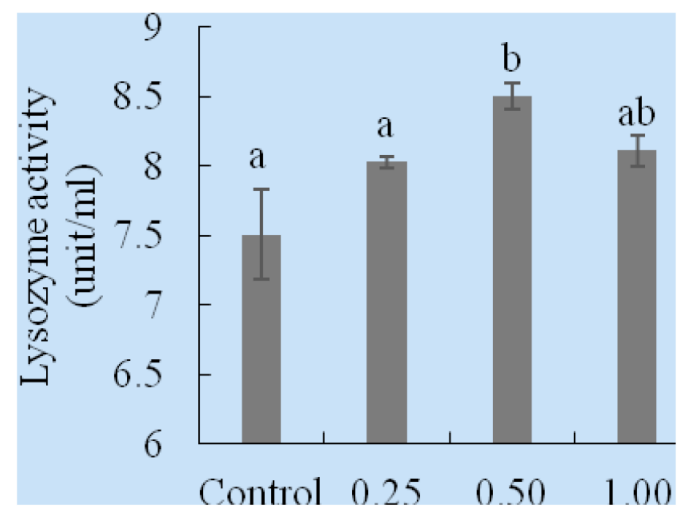

(C)

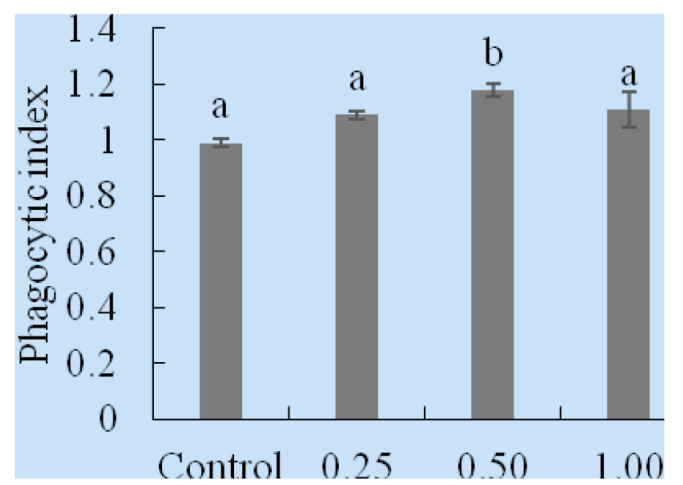

(B)

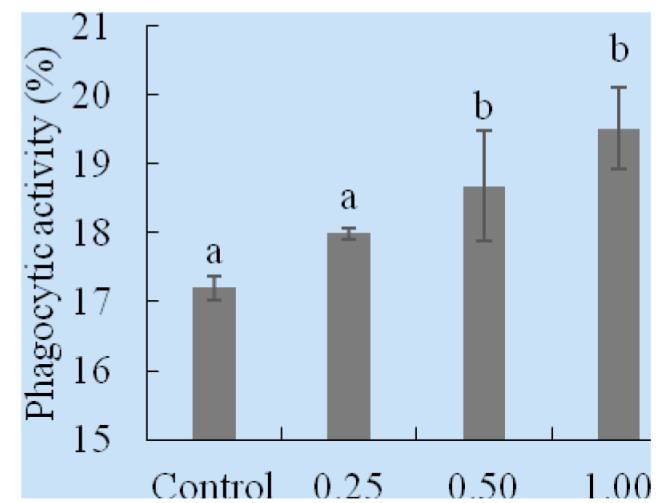

(D)

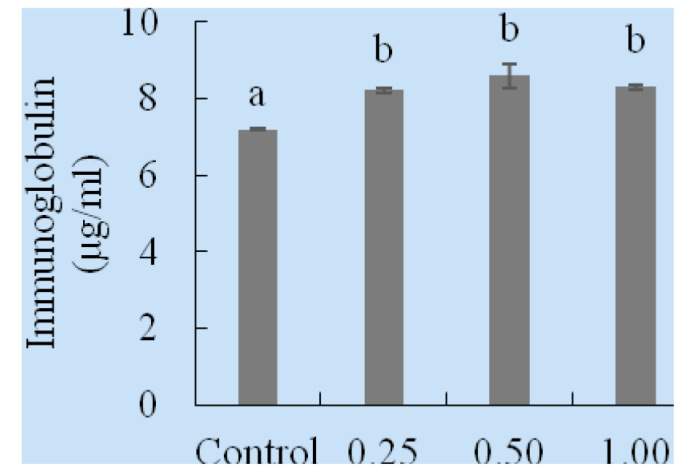

Figure 1. Effect of herbal EOs blend $(\mathrm{ml} / \mathrm{kg})$ on the blood immunity of Nile tilapia. Bars showing means \pm S.E. with different letters differ significantly $(\mathrm{P}<0.05)$ 
(A)

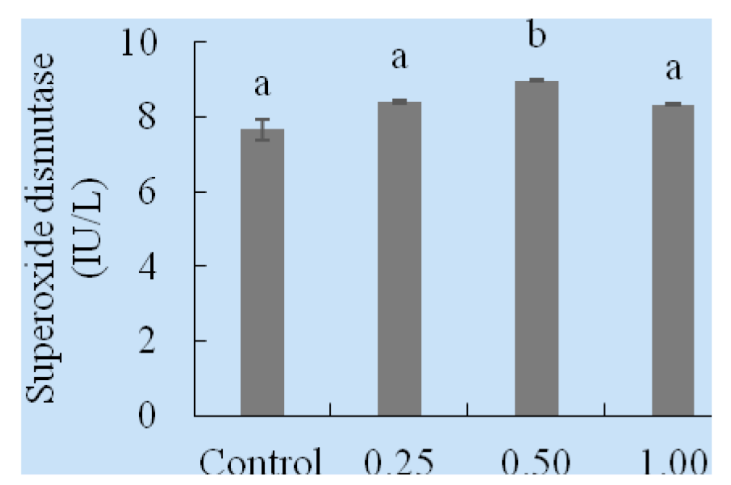

(B)

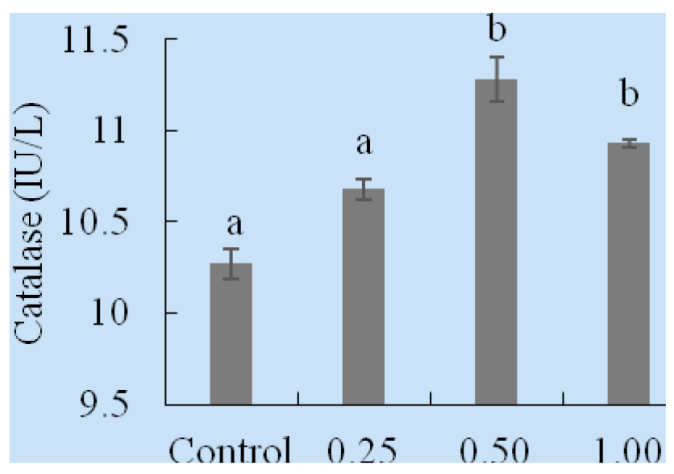

(C)



Figure 2. Effect of herbal EOs blend $(\mathrm{ml} / \mathrm{kg})$ on the blood antioxidative capacity of Nile tilapia. Bars showing means \pm S.E. with different letters differ significantly $(\mathrm{P}<0.05)$


Figure 3. Histomorphology of the Nile tilapia intestine showing the histological alignment in the control fish (A) as well as the herbal essential oil-subjected groups (B, C, and D) in increasing doses $(0.25 \mathrm{ml}, 0.5 \mathrm{ml}$, and $1 \mathrm{ml} / \mathrm{kg}$ respectively). The intestine looked intact and formed of the intestinal villi (V), lamina propria sub mucosa (P), tunica muscularis (M) and tunica serosa (blue arrow). The herbal essential displayed clear improvement of length and branching of the intestinal villi and arrangement of enterocytes (blue arrowhead). Stain H\&E. Bar: $100 \mu \mathrm{m}$ 

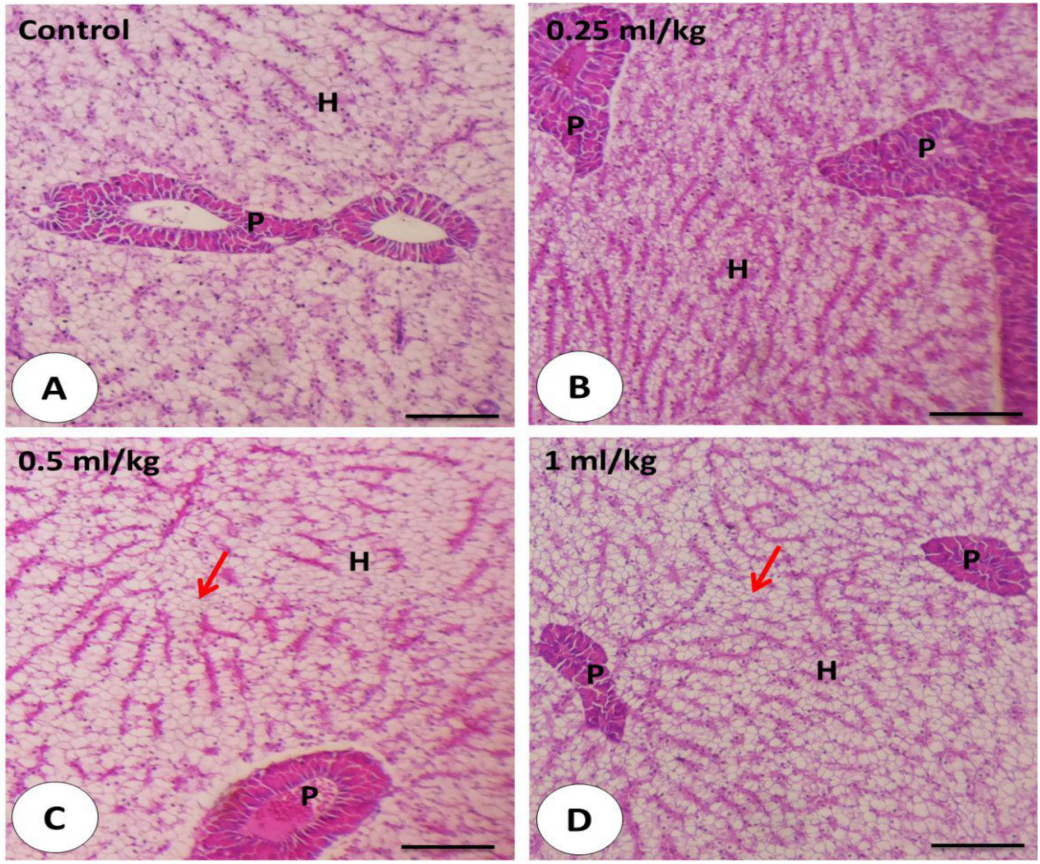

Figure 4. Histomorphology of the Nile tilapia liver showing the histological structure in the control fish (A) as well as the herbal essential oilsubjected groups (B, C, and D) in increasing doses $(0.25 \mathrm{ml}, 0.5 \mathrm{ml}$, and $1 \mathrm{ml} / \mathrm{kg}$ respectively). The hepatocytes arranged in cords $(\mathrm{H})$ around the blood sinusoids and the pancreatic acinar cells (P) arranged around the afferent portal vein. The spongy architecture of hepatopancreas in the control fish was improved in the herbal essential oil-subjected fish (B) with mild fatty deposition (red arrow) in the moderate and high doses (C- D). Stain H\&E. Bar: $100 \mu \mathrm{m}$
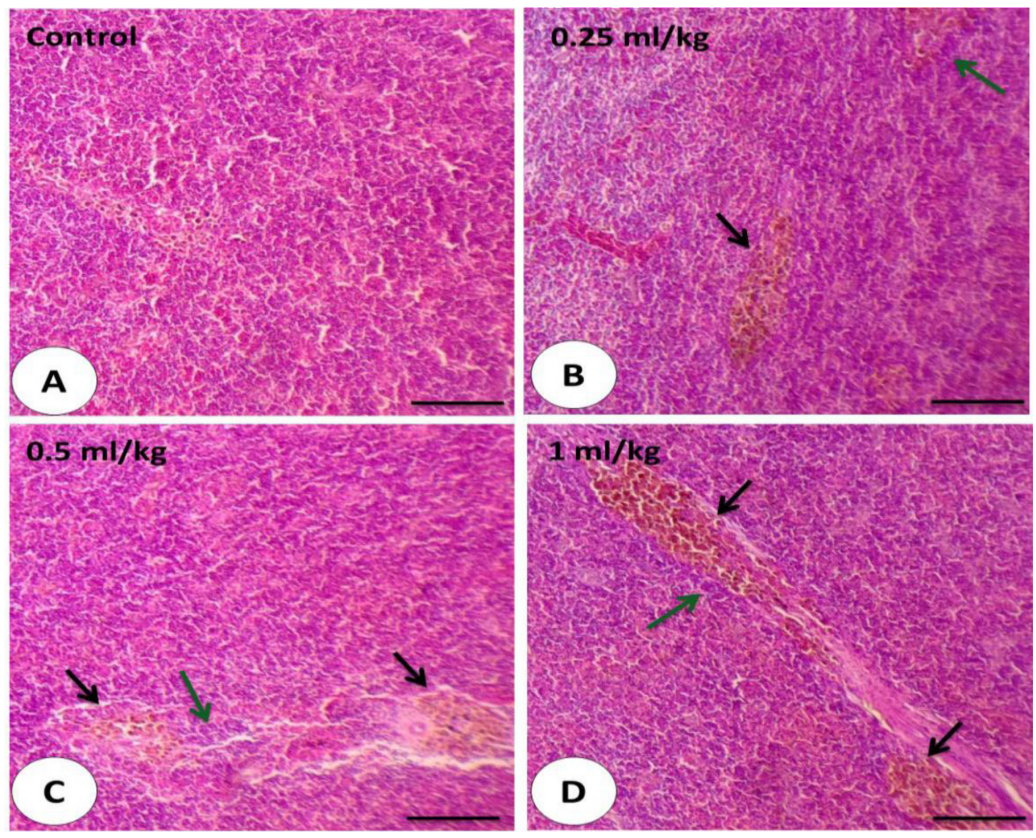

Figure 5. Histomorphology of the spleen of the Nile tilapia showing the histological structure in the control fish (A) as well as the herbal essential oil-subjected groups (B, C, and D) in increasing doses $(0.25 \mathrm{ml}, 0.5 \mathrm{ml}$, and $1 \mathrm{ml} / \mathrm{kg}$ respectively). The splenic tissue has relatively normal appearance with increased melanomacrophages (black arrow) and lymphocytic infiltration (green arrow) with increased dose of herbal essential oil mixture. Stain H\&E. bar: $100 \mu \mathrm{m}$

\section{Discussion}

The blue aquaculture industry concept focuses on producing healthy finfish species with limited antibiotics (Zhao et al., 2020). It means looking for natural substances that can replace chemotherapies becomes a strategic procedure for sustainable aquaculture (Zhu, 2020). In this regard, great efforts were followed to test various additives such as medicinal herbs and their extracts (Lieke et al., 2020). The studies concluded that using phytogenics as a powder, methanolic extracts, and essential oils (EOs) markedly impacted the growth performances, health sta- 
tus, and resistance against infection (Domínguez-Borbor et al., 2020). Using blended synergistic EOs could be an innovative approach applied in the field with observable results. This study investigated the possibility of using a mixture of EOs containing carvacrol, oregano, 1,8 cineol, thymol, pinene, pinene $\beta$, limonene, and propylene glycol in the diets of Nile tilapia for the first time.

The growth performance (FBW, WG, and SGR) was meaningfully enhanced in the group of fish delivered the blended mixture of EOs concerning the control group. The results agreed with several studies that concluded enhanced growth performance in finfish species fed dietary EOs and attributed the enhanced growth rate to the efficient utilization of feed (Aanyu et al., 2018; El-Hawarry et al., 2018). In 45 days feeding trial, Nile tilapia fed dietary EO extracted from Aloysia triphylla showed enhanced growth performance (de Souza et al., 2020). Another study illustrated the positive effect of EOs derived from clove basil and ginger on the growth performance of Nile tilapia after 55 days (Brum et al., 2017). Likewise, Amer et al. (2018) stated that Nile tilapia delivered cinnamaldehyde and thymol EO showed enhanced growth performance. The influence of EOs on the growth performance begins with enhancing the digestion and absorption of feed in the intestines of fish (Thapa et al., 2012). Indeed, EOs increase the palatability of feeds and inhibit pathogenic microorganisms, resulting in increased activity of beneficial bacteria. Consequently, beneficial bacteria secrete digestive enzymes that cause good digestion and utilization of feeds (Reverter et al., 2014; Zeng et al., 2015). Interestingly, this study showed enhanced feed intake, and FCR in Nile tilapia fed the blend of EOs, which is in line with enhanced growth performance under the current trial conditions. The enhanced feed utilization was also observed in other studies that evaluated EOs in finfish species (de Oliveira et al., 2020; Rattanachaikunsopon and Phumkhachorn, 2010).

The results also showed enhanced amylase and lipase activities in serum samples of Nile tilapia fed a dietary blend of EOs. The results are similar to de Souza et al. (2020), who stated enhanced digestive enzyme activity in Nile tilapia fed dietary Aloysia triphylla EOs. The inclusion of EOs in aquafeed balances intestinal microbiota's abundance and allows beneficial bacteria to secrete digestive enzymes involved in feed digestion (Giannenas et al., 2012; Zhang et al., 2020). Concisely, the results showed enhanced histological features of intestines of Nile tilapia fed EOs, which confirm the obtained feed utilization results. The well-being of fish intestinal features illustrates the protective role of EOs on villi's absorption area, which allows increased permeability of digested nutrients to the entire body, resulting in enhanced metabolic functions (Dawood, 2021). Concurrent with the present study, Abd El-Naby et al. (2020) concluded that thymol EO enhanced intestinal features in Nile tilapia.

The incorporation of EOs in aquafeed has been recognized as a blood metabolic regulator and immunomodulator for the physiological condition of finfish species (Valladão et al., 2019). For example, high levels of hematocrit (HCT) and hemoglobin $(\mathrm{Hb})$ indicate no anemic features with good metabolic function (Hrubec et al., 2001). Further, high red and white blood cell count (RBCs and WBCs) usually tended to enhance feed utilization and consequently increased immunity (Dawood et al., 2020). This study showed increased HCT, Hb, WBCs, and RBCs in Nile tilapia fed a blend of EOs, which refer to fish's enhanced metabolic, physiological, and immunological condition under the current trial consequences. Similar results were observed in Nile tilapia fed EOs of clove basil (Brum et al., 2017), Lippia sidoides and Mentha piperita (de Oliveira Hashimoto et al., 2016), and Aloysia triphylla (de Souza et al., 2020).

The detected blood biochemical indices tended to be within the healthy fish's average values without marked differences among the groups. The blood protein profile (total protein, albumin, and globulin), total cholesterol, triglycerides, urea, uric acid, and creatinine displayed normal values indicating the absence of immunosuppression, kidney failure, and malnutrition in Nile tilapia fed a dietary blend of EOs. Additionally, the liver function enzymes (ALT and AST) showed no abnormalities with similar normal features in the histological sections of the hepatic tissue in fish delivered the blend of EOs in this study. No abnormal features were observed in the liver tissue, and regulated ALT and AST confirm the healthy status of tilapia and the lack of liver damage. Similar results were also observed in Nile tilapia fed Mentha piperita and Melaleuca alternifolia EOs (Valladão et al., 2017).

Lysozyme and phagocytic activities are two immune responses associated with fish's immune defense against infection with pathogens (Brum et al., 2017; de Souza et al., 2020). The lysozyme activity leakage the cell walls of bacteria and suppress its activity during the infection (Grinde et al., 1988). Phagocytic activity is another innate immune response to defend against infection (Wu et al., 2020). The results showed enhanced lysozyme, and phagocytic activities in the blood of Nile tilapia fed EOs indicated enhanced immune response and tolerance against possible infection. These results agree with Amer et al. (2018), who reported enhanced lysozyme and phagocytic activities in Nile tilapia fed dietary cinnamaldehyde and thymol EOs. The total immunoglobulins (IgM) are another biochemical molecule involved in regulating the immune-related derivatives in fish's blood. This study showed enhanced IgM in fish delivered a blend of EOs, indicating enhanced metabolic and immune functions. Similar enhanced IgM levels were reported in Nile tilapia fed cinnamaldehyde and thymol EOs (Amer et al., 2018). The enhanced immunity in Nile tilapia fed a blend of EOs in this study is probably associated with enhanced local intestinal immunity resulting from the positive impact of herbal EOs (Mason and Huffnagle, 2009).

Herbal EOs are famous for their antioxidative potential accredited to the high content of polyphenols 
(Ahmadifar et al., 2020; García Beltrán et al., 2020). In case of stress, fish secretes antioxidative enzymes (SOD and CAT) to scavenge the free radicals that induce lipid peroxidation in the entire cells and consequently DNA damage (Mohammadi et al., 2020). The level of lipid peroxidation can be expressed by the malondialdehyde level (MDA). The SOD and CAT were markedly influenced by feeding a blend of EOs, while the MDA level was significantly decreased. Concurrent with these results, Amer et al. (2018) reported reduced MDA levels in fish fed dietary herbal EOs. Further, Aanyu et al. (2018) reported enhanced CAT in Nile tilapia fed limonene and thymol EOs, while El-Hawarry et al. (2018) indicated enhanced SOD in Nile tilapia fed oregano EO.

The overall results of the present study showed marked enhancements in growth performance, feed intake, digestive enzyme activity in Nile tilapia treated with a blend of EOs. Further, the dietary mixture of EO led to regulated hematological and biochemical blood indices with meaningful activation of blood immune and antioxidative responses. The obtained results confirm the functionality and the synergistic effects of the blend of EOs used in this study. The potential roles of EOs primarily affect the local intestinal immunity and nutritional capacity resulting from the antibacterial efficiency (Roques et al., 2020). Concurrently, the abundance of beneficial bacteria increases and results in high digestion and absorption of nutrients, thereby high metabolic and physiological function (Dawood, 2021). Thus, it can be hypothesized that the blend of EOs is an efficient additive in improving feed utilization, intestinal immunity, and the entire body immunity of Nile tilapia.

\section{Conclusion}

It is worth noting that feeding with a blend of EOs is highly recommended to enhance Nile tilapia's performance. The growth performance and feed efficiency of fish fed $0.5-1 \mathrm{ml} / \mathrm{kg}$ were best among the groups. Additionally, the blood bio-immunological showed enhanced responses by a dietary blend of EOs. Besides, the antioxidative status was enhanced by dietary EOs. However, further future studies are required to understand EO's mode of action on the performances of finfish species.

\section{Conflict of interest}

The authors declare that there is no conflict of interest.

\section{References}

Aanyu M., Betancor M.B., Monroig O. (2018). Effects of dietary limonene and thymol on the growth and nutritional physiology of Nile tilapia (Oreochromis niloticus). Aquaculture, 488: 217-226.

Abd El-Naby A.S., Al-Sagheer A.A., Negm S.S., Naiel M.A.E. (2020). Dietary combination of chitosan nanoparticle and thymol affects feed utilization, digestive enzymes, antioxidant status, and intes- tinal morphology of Oreochromis niloticus. Aquaculture, 515: 734577-734577.

Abdel Rahman A.N., Abdellatief S.A., Mahboub H.H.H. (2017). Protection of Nile tilapia, Oreochromis niloticus from aflatoxin B1 toxicity by dietary supplementation with Fennel essential oil and Saccharomyces cerevisiae. T. Egypt. J. Aquat. Res., 43: 235-240.

Acar U., Kesbiç O.S., Yilmaz S., Gültepe N., Türker A. (2015). Evaluation of the effects of essential oil extracted from sweet orange peel (Citrus sinensis) on growth rate of tilapia (Oreochromis mossambicus) and possible disease resistance against Streptococcus iniae. Aquaculture, 437: 282-286.

Ahmadifar E., Yousefi M., Karimi M., Fadaei Raieni R., Dadar M., Yilmaz S., Dawood M.A., Abdel-Latif H.M. (2020). Benefits of dietary polyphenols and polyphenol-rich additives to aquatic animal health: an overview. Rev. Fish. Sci. Aquac., 1-34

Ahmadifar E., Pourmohammadi Fallah H., Yousefi M., Dawood M.A.O., Hoseinifar S.H., Adineh H., Yilmaz S., Paolucci M., Doan H.V. (2021). The gene regulatory roles of herbal extracts on the growth, immune system, and reproduction of fish. Animals, 11 .

Alagawany M., Farag M.R., Abdelnour S.A., Dawood M.A.O., Elnesr S.S., Dhama K. (2020). Curcumin and its different forms: A review on fish nutrition. Aquaculture, 736030.

Amer S.A., Metwally A.E., Ahmed S.A.A. (2018). The influence of dietary supplementation of cinnamaldehyde and thymol on the growth performance, immunity and antioxidant status of monosex Nile tilapia fingerlings (Oreochromis niloticus). Egypt. J. Aquat. Res., 44: 251-256.

AOAC (2012). Official Methods of Analysis of AOAC International. 19th ed. AOAC International, Gaithersburg, Maryland, USA. www.eoma.aoac.org

Aydin B., Barbas L.A.L. (2020). Sedative and anesthetic properties of essential oils and their active compounds in fish: A review. Aquaculture, 520: 734999 .

Brandão F.R., Farias C.F.S., de Melo Souza D.C., de Oliveira M.I.B., de Matos L.V., Majolo C., de Oliveira M.R., Chaves F.C.M., de Almeida O'Sullivan F.L., Chagas E.C. (2021). Anesthetic potential of the essential oils of Aloysia triphylla, Lippia sidoides and Mentha piperita for Colossoma macropomum. Aquaculture, 534: 736275 .

Brum A., Pereira S.A., Owatari M.S., Chagas E.C., Chaves F.C.M., Mouriño J.L.P., Martins M.L. (2017). Effect of dietary essential oils of clove basil and ginger on Nile tilapia (Oreochromis niloticus) following challenge with Streptococcus agalactiae. Aquaculture, 468: 235-243.

Cai W.-Q., Li S.-F., Ma J.-Y. (2004). Diseases resistance of Nile tilapia (Oreochromis niloticus), blue tilapia (Oreochromis aureus) and their hybrid (female Nile tilapia $\times$ male blue tilapia) to Aeromonas sobria. Aquaculture, 229: 79-87.

Costa C.M.d.S., da Cruz M.G., Lima T.B.C., Ferreira L.C., Ventura A.S., Brandão F.R., Chagas E.C., Chaves F.C.M., Martins M.L., Jerônimo G.T. (2020). Efficacy of the essential oils of Mentha piperita, Lippia alba and Zingiber officinale to control the acanthocephalan Neoechinorhynchus buttnerae in Colossoma macropomum. Aquacult. Rep., 18: 100414.

Dawood M.A.O. (2021). Nutritional immunity of fish intestines: important insights for sustainable aquaculture. Rev. Aquacult., 13: 642-663.

Dawood M.A.O., Koshio S., Esteban M.Á. (2018). Beneficial roles of feed additives as immunostimulants in aquaculture: a review. Rev. Aquacult., 10: 950-974.

Dawood M.A., AbdEl-Kader M.F., Moustafa E.M., Gewaily M.S., Abdo S.E. (2020). Growth performance and hemato-immunological responses of Nile tilapia (Oreochromis niloticus) exposed to deltamethrin and fed immunobiotics. Environ. Sci. Pollut. Res., $1-10$.

Dawood M.A.O., El Basuini M.F., Zaineldin A.I., Yilmaz S., Hasan M.T., Ahmadifar E., El Asely A.M., Abdel-Latif H.M.R., Alagawany M., Abu-Elala N.M., Van Doan H., Sewilam H. (2021). Antiparasitic and antibacterial functionality of essential oils: An alternative approach for sustainable aquaculture. Pathogens, 10: 185. 
de Oliveira Hashimoto G.S., Neto F.M., Ruiz M.L., Acchile M., Chagas E.C., Chaves F.C.M., Martins M.L. (2016). Essential oils of Lippia sidoides and Mentha piperita against monogenean parasites and their influence on the hematology of Nile tilapia. Aquaculture, 450: 182-186.

de Oliveira S.T.L., Soares R.A.N., de Negreiros Sousa S.M., Fernandes A.W.C., Gouveia G.V., da Costa M.M. (2020). Natural products as functional food ingredients for Nile tilapia challenged with Aeromonas hydrophila. Aquacult. Int., 28: 913-926.

de Souza R.C., Baldisserotto B., Melo J.F.B., da Costa M.M., de Souza E.M., Copatti C.E. (2020). Dietary Aloysia triphylla essential oil on growth performance and biochemical and haematological variables in Nile tilapia. Aquaculture, 519: 734913.

Dinardo F.R., Deflorio M., Casalino E., Crescenzo G., Centoducati G. (2020). Effect of feed supplementation with Origanum vulgare L. essential oil on sea bass (Dicentrarchus labrax): A preliminary framework on metabolic status and growth performances. Aquacult. Rep., 18: 100511.

Domínguez-Borbor C., Sánchez-Rodríguez A., Sonnenholzner S., Rodríguez J. (2020). Essential oils mediated antivirulence therapy against vibriosis in Penaeus vannamei. Aquaculture, 529: 735639.

Doumas B.T., Biggs H.G. (1972). Editors. Standard methods of clinical chemistry. Academic Press, New York.

Doumas B.T., Bayse D.D., Carter R.J., Peters T., Schaffer R. (1981). A candidate reference method for determination of total protein in serum. I. Development and validation. Clin. Chem., 27: 16421650.

El-Hawarry W.N., Mohamed R.A., Ibrahim S.A. (2018). Collaborating effects of rearing density and oregano oil supplementation on growth, behavioral and stress response of Nile tilapia (Oreochromis niloticus). Egypt. J. Aquat. Res., 44: 173-178.

Ellis A. (1990). In: Techniques in fish immunology, Stolen J.S., Fletcher T.C., Anderson D.P., Roberson B.S., Van Muiswinkel W.B. (eds). SOS Publications, Fair Haven, pp. 101-103.

Elumalai P., Kurian A., Lakshmi S., Faggio C., Esteban M.A., Ringø E. (2020). Herbal immunomodulators in aquaculture. Rev. Fish Sci. Aquac., 1-25.

Erkinharju T., Dalmo R.A., Hansen M., Seternes T. (2021). Cleaner fish in aquaculture: review on diseases and vaccination. Rev. Aquacult., 13: 189-237.

García Beltrán J.M., Silvera D.G., Ruiz C.E., Campo V., Chupani L., Faggio C., Esteban M.Á. (2020). Effects of dietary Origanum vulgare on gilthead seabream (Sparus aurata L.) immune and antioxidant status. Fish Shellfish Immunol., 99: 452-461.

Gewaily M.S., Abumandour M.M. (2020). Gross morphological, histological and scanning electron specifications of the oropharyngeal cavity of the hooded crow (Corvus cornix pallescens). Anat. Histol. Embryol., 50: 72-83.

Giannenas I., Triantafillou E., Stavrakakis S., Margaroni M., Mavridis S., Steiner T., Karagouni E. (2012). Assessment of dietary supplementation with carvacrol or thymol containing feed additives on performance, intestinal microbiota and antioxidant status of rainbow trout (Oncorhynchus mykiss). Aquaculture, 350-353: 26-32.

Grinde B., Lie Ø., Poppe T., Salte R. (1988). Species and individual variation in lysozyme activity in fish of interest in aquaculture. Aquaculture, 68: 299-304.

Habiba M.M., Hussein E.E., Ashry A.M., El-Zayat A.M., Hassan A.M., El-Shehawi A.M., Sewilam H., Van Doan H., Dawood M.A.O. (2021). Dietary cinnamon successfully enhanced the growth performance, growth hormone, antibacterial capacity, and immunity of European sea bass (Dicentrarchus labrax). Animals, 11.

Hernández-Contreras Á., Hernández M.D. (2020). Chapter 14 - Application of aromatic plants and their extracts in aquaculture. In: Feed Additives, Florou-Paneri P., Christaki E., Giannenas I. (eds). Academic Press, pp. 239-259.

Houston A. (1990). Blood and circulation/Methods for fish biology. NY: Amer. Fish. Society.

Hrubec T.C., Smith S.A., Robertson J.L. (2001). Age-related changes in hematology and plasma chemistry values of hybrid striped bass (Morone chrysops X Morone saxatilis). Vet. Clin. Pathol., 30: $8-15$.

Kawahara E., Ueda T., Nomura S. (1991). In vitro phagocytic activity of white-spotted char blood cells after injection with Aeromonas salmonicida Extracellular Products. Fish Pathol., 26: 213-214.

Lieke T., Meinelt T., Hoseinifar S.H., Pan B., Straus D.L., Steinberg C.E.W. (2020). Sustainable aquaculture requires environmentalfriendly treatment strategies for fish diseases. Rev. Aquacult., 12: 943-965.

Lulijwa R., Rupia E.J., Alfaro A.C. (2020). Antibiotic use in aquaculture, policies and regulation, health and environmental risks: a review of the top 15 major producers. Rev. Aquacult., 12: 640-663.

Mabrok M.A.E., Wahdan A. (2018). The immune-modulatory effect of oregano (Origanum vulgare L.) essential oil on Tilapia zillii following intraperitoneal infection with Vibrio anguillarum. Aquacult. Int., 26: 1147-1160.

Magouz F.I., Mahmoud S.A., El-Morsy R.A., Paray B.A., Soliman A.A., Zaineldin A.I., Dawood M.A. (2021). Dietary menthol essential oil enhanced the growth performance, digestive enzyme activity, immune-related genes, and resistance against acute ammonia exposure in Nile tilapia (Oreochromis niloticus). Aquaculture, 530: 735944.

Mason K.L., Huffnagle G.B. (2009). Control of mucosal polymicrobial populations by innate immunity. Cell. Microbiol., 11: 1297-1305.

Mengistu S.B., Mulder H.A., Benzie J.A.H., Komen H. (2020). A systematic literature review of the major factors causing yield gap by affecting growth, feed conversion ratio and survival in Nile tilapia (Oreochromis niloticus). Rev. Aquacult., 12: 524-541.

Metian M., Troell M., Christensen V., Steenbeek J., Pouil S. (2020). Mapping diversity of species in global aquaculture. Rev. Aquacult., 12: 1090-1100.

Mohammadi G., Rafiee G., El Basuini M.F., Abdel-Latif H.M.R., Dawood M.A.O. (2020). The growth performance, antioxidant capacity, immunological responses, and the resistance against Aeromonas hydrophila in Nile tilapia (Oreochromis niloticus) fed Pistacia vera hulls derived polysaccharide. Fish Shellfish Immunol., 106: 36-43.

Ning L., Zhang X., Zhang D., Hu Y., Li Y. (2021). The benefits of blend essential oil for GIFT tilapia on the digestion, antioxidant, and muscle quality during cold storage. Aquaculture, 533: 736097.

NRC (2011). National Research Council - nutrient requirements of fish and shrimp. National Academies Press.

Postay L.F., Cabral D.S., Heringer O.A., Vieira L.V., de Moraes L.R., Freitas G., Gomes L.C. (2021). The effectiveness of surfactants applied with essential oil of Lippia alba in the anesthesia of Nile tilapia (Oreochromis niloticus) and their toxicity assessment for fish and mammals. Environ. Sci. Pollut. Res., 28: 1022410233.

Rattanachaikunsopon P., Phumkhachorn P. (2010). Assessment of synergistic efficacy of carvacrol and cymene against Edwardsiella tarda in vitro and in Tilapia (Oreochromis niloticus). Afr. J. Microbiol. Res., 4.

Reverter M., Bontemps N., Lecchini D., Banaigs B., Sasal P. (2014). Use of plant extracts in fish aquaculture as an alternative to chemotherapy: Current status and future perspectives. Aquaculture, 433: 50-61.

Roques S., Deborde C., Richard N., Skiba-Cassy S., Moing A., Fauconneau B. (2020). Metabolomics and fish nutrition: a review in the context of sustainable feed development. Rev. Aquacult., 12: 261-282.

Sönmez A.Y., Bilen S., Albayrak M., Yılmaz S., Biswas G., Hisar O., Yanık T. (2015). Effects of dietary supplementation of herbal oils containing 1,8-cineole, carvacrol or pulegone on growth performance, survival, fatty acid composition, and liver and kidney histology of rainbow trout (Oncorhynchus mykiss) fingerlings. Turk. J. Fish. Aquat. Sci., 15: 813-819.

Thapa D., Losa R., Zweifel B., John Wallace R. (2012). Sensitivity of pathogenic and commensal bacteria from the human colon to essential oils. Microbiology (United Kingdom), 158: 2870-2877.

Valladão G.M.R., Gallani S.U., Pala G., Jesus R.B., Kotzent S., Costa J.C., Silva T.F.A., Pilarski F. (2017). Practical diets with essential oils of plants activate the complement system and alter the intestinal morphology of Nile tilapia. Aquacult. Res., 48: $5640-5649$. 
Valladão G.M.R., Gallani S.U., Kotzent S., Assane I.M., Pilarski F. (2019). Effects of dietary thyme essential oil on hemato-immunological indices, intestinal morphology, and microbiota of Nile tilapia. Aquacult. Int., 27: 399-411.

Wu L., Qin Z., Liu H., Lin L., Ye J., Li J. (2020). Recent advances on phagocytic B cells in teleost fish. Front. Immunol., 11: 824-824.

Zeng Z., Zhang S., Wang H., Piao X. (2015). Essential oil and aromatic plants as feed additives in non-ruminant nutrition: a review. J. Anim. Sci. Biotechnol., 6: 7.

Zhang R., Wang X.W., Liu L.L., Cao Y.C., Zhu H. (2020). Dietary oregano essential oil improved the immune response, activity of digestive enzymes, and intestinal microbiota of the koi carp, Cyprinus carpio. Aquaculture, 518: 734781.

Zhao Y., Yang Q.E., Zhou X., Wang F.-H., Muurinen J., Virta M.P., Brandt K.K., Zhu Y.-G. (2020). Antibiotic resistome in the livestock and aquaculture industries: Status and solutions. Crit. Rev. Environ. Sci. Technol., 1-38.

Zhu F. (2020). A review on the application of herbal medicines in the disease control of aquatic animals. Aquaculture, 526: 735422.

Received: 14 V 2021

Accepted: 9 VIII 2021 